\title{
Suspected food allergy responding to fluconazole?
}

\author{
Alexander Salava*, Antti Lauerma and Paula Kauppi \\ *Correspondence: alexander.salava@hus.fi

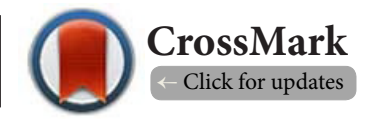

Department of Allergology, Helsinki University Hospital, Helsinki, Finland.

\begin{abstract}
We present a case report of a patient with chronic gastrointestinal symptoms who was referred to the allergologist because of suspected food allergy. In this setting, irritable bowel syndrome, reflux disease, lactose intolerance, food allergy, mastocytic enterocolitis, Crohn's disease and coeliac disease are frequently considered as diagnostic possibilities in young patients. In addition, stool samples may be used to rule out infectious diseases such as salmonella infection. This case proved unusual in excluding all of the aforementioned possibilities and shows the importance of adequate consideration of differential diagnostics if common explanations of chronic gastrointestinal symptoms remain inconclusive.
\end{abstract}

Keywords: Food allergy, fluconazole, chronic gastrointestinal symptoms, HIV-infection

\section{Case presentation}

\section{Suspected food allergy responding to fluconazole?}

A 32-year old Caucasian male was referred to the department of allergology because of chronic gastrointestinal complaints and suspected food allergy. Over the preceding 2-3 years, the patient complained of intermittent pain in the abdomen and epigastrium, accompanied by flatulence and episodes of nonbloody diarrhea and constipation. The patient had associated these symptoms with consumption of different foodstuffs, e.g., wheat, milk, different vegetables, meat and nuts. Family history was negative for relevant gastrointestinal disorders.

Investigations including gastroscopy, colonoscopy, stool bacteriology/parasites, serology for coeliac disease and genetic testing for primary hypolactasia had been normal in the previous 1-2 years. The preliminary diagnosis of the referring gastroenterologist was irritable bowel syndrome. Based on good responses to 2-3 week long empiric courses of peroral fluconazole (prescribed by the referring gastroenterologist), a diagnosis of chronic intestinal yeast overgrowth had also been considered.

On clinical examination, the patient's vital signs were normal and the abdomen was soft, but slightly tender on palpation. There was no jaundice detected and skin and mucosa were normal upon inspection. Genital and peri-anal examination showed no pathological findings.

Laboratory findings at the first visit showed a slight lymphocytopenia (blood lymphocytes $0.93 \times 10^{9} / \mathrm{l}$ ), normochromic and normocytic anemia (blood hemoglobin $113 \mathrm{~g} / \mathrm{l}, \mathrm{MCH} 30 \mathrm{pg}$,
MCV $89 \mathrm{fl}$ ), thrombocytopenia (platelets $\left.116 \times 10^{9} / \mathrm{l}\right)$, with normal total blood leukocytes $\left(3.6 \times 10^{9} / \mathrm{I}\right)$ and otherwise normal differential blood count. Levels of $C$-reactive protein were normal $(<3 \mathrm{mg} / \mathrm{dl})$, but the erythrocyte sedimentation rate was increased (ESR $83 \mathrm{~mm} /$ first hour). Serum immunoglobulin levels were not measured. Plasma concentrations of bilirubin, amylase, creatinine, glucose, ALT, AST, ALP, GGT, cholesterol, triglycerides were within normal limits. Fecal calprotectin was not elevated $(<5 \mu \mathrm{g} / \mathrm{g})$. Urine standard test strip and sediment analysis were normal.

Skin prick tests with common aeroallergens were negative. In addition, skin prick tests with several foodstuffs were negative, including egg white, fish (cod), gliadin, milk, peanut, shrimp, soy, wheat, potato, celery, carrot, parsnip, banana, apple, pea, kiwi, hazelnut, curry, almond, peanut, Swedish turnip, parsley, tomato, sweet pepper, garlic, allspice, white pepper, paprika, mustard, vanilla, orange, strawberry, rosé pepper and red chilli.

The allergologist ordered a single blood test which explained the likely cause of the symptoms and made further allergy testing unnecessary. What test did he order?

\section{Discussion \\ A HIV-test}

The fact, that our patient was in a stable relationship with another male lead the allergologist to order an HIV-test, which was positive (HIV-ELISA).

Further investigations showed the presence of HIV p24 antigen in the patient's serum $(31 \mathrm{pg} / \mathrm{ml})$ and positive $\mathrm{lg} G$ responses 
Salava et al. Journal of Allergy and Asthma 2015,

to the HIV-1 antigens gp41, p31 and p24 (HIV-Western blot). This serological profile is typically seen in later stages of HIV infection. The CD4-positive T-lymphocyte count was markedly decreased at $0.063 \times 10^{9} / \mathrm{I}$ and HIV1 viral load was $1,418,511$ copies/ml.

In light of these findings, the patient's chronic gastrointestinal symptoms were considered likely to be caused by chronic suppression of T-cell mediated immunity, although there was no history of opportunistic infections apparent. The reasons for a good clinical response to fluconazole could be not be confirmed, but could conceivably be explained by treatment of occult intestinal yeast infection (e.g., Cryptococcus or Candida). In patients with HIV-infection chronic gastrointestinal symptoms are frequent. Among the many causes, yeast infections (e.g., Cryptococcus or Candida) and intestinal Histo plasmosis have been recognized and may respond to fluconazole and other antifungal therapies $[1,2]$. It should however be appreciated that food allergy has been reported in HIV-infected individuals with the same prevalence as in non-HIV-infected [3]. Skin prick tests with common aeroallergens, foodstuffs, vegetables and spices were all negative in this case and thus gastrointestinal symptoms could not be explained by food allergy. Consequently, it would appear that the patient had falsely associated his chronic gastrointestinal symptoms with allergy to one or more specific foodstuffs.

Our patient was referred to a specialist for infectious diseases and the symptoms showed a good response (reduction of viral load and increase of CD4 count) during follow up of anti-retroviral therapy with zidovudin, lamivudin, abacavir (Trizivivi $^{\mathrm{TM}}$ ) and nevirapin (Viramune ${ }^{\mathrm{TM}}$ ) $[4,5]$.

Allergies and allergic symptoms are common but the exact prevalence of food allergy has been difficult to estimate because of differences in study protocols and low participation rate in studies. Altogether, self-reported life-time prevalence of food allergy has been estimated to be up to $6.0 \%$ whereas food-challenge-defined allergy has been estimated to occur in up to $0.6 \%$ of the population [6]. The prevalence of coeliac disease has been estimated to be up to $2 \%$ and HIV-infection less than $1 \%$ in western countries.

The case presented here shows the importance of a comprehensive consideration of differential diagnostic options in cases of suspected food allergy. A HIV-test should be considered particularly in high-risk patient groups (e.g., homosexual individuals and intravenous drug users) who are referred to the allergologist for investigation of gastrointestinal symptoms and allergy testing [7].

\section{Conclusion}

Chronic gastrointestinal symptoms are a common clinical problem with a wide range of differential diagnoses. In patients with suspected food allergies and negative allergy tests other causes should be considered. HIV-infection can cause chronic gastrointestinal symptoms and a HIV-test should be carried out particularly in patients of risk groups.

\section{List of abbreviations}

HIV: Human immunodeficiency virus $\mathrm{MCH}$ : Mean corpuscular haemoglobin MCV: Mean corpuscular volume ESR: Erythrocyte sedimentation rate ELISA: Enzyme-linked immunoabsorbent assay

ALAT: Alanine-amino-transferase

AST: Aspartate-amino-transferase

ALP: Alkaline phosphatise

GGT: Gamma-glutamyl-transferase

Competing interests

The authors declare that they have no competing interests.

Authors' contributions

\begin{tabular}{|l|c|c|c|}
\hline Authors' contributions & AS & AL & PK \\
\hline Research concept and design & $\checkmark$ & -- & -- \\
\hline Collection and/or assembly of data & $\checkmark$ & -- & -- \\
\hline Data analysis and interpretation & $\checkmark$ & -- & $\checkmark$ \\
\hline Writing the article & $\checkmark$ & -- & $\checkmark$ \\
\hline Critical revision of the article & $\checkmark$ & $\checkmark$ & $\checkmark$ \\
\hline Final approval of article & $\checkmark$ & $\checkmark$ & $\checkmark$ \\
\hline
\end{tabular}

Publication history

Editor: Sunit P. Jariwala, Albert Einstein College of Medicine, USA. Received: 06-Mar-2015 Final Revised: 07-Apr-2015

Accepted: 21-Apr-2015 Published: 28-Apr-2015

\section{References}

1. Thompson T, Lee MG, Clarke T, Mills $M$, Wharfe $G$ and Walters $C$. Prevalence of gastrointestinal symptoms among ambulatory HIV patients and a control population. Ann Gastroenterol. 2012; 25:243-248. | PubMed Abstract | PubMed Full Text

2. Bhaijee F, Subramony C, Tang SJ and Pepper DJ. Human immunodeficiency virus-associated gastrointestinal disease: common endoscopic biopsy diagnoses. Patholog Res Int. 2011; 2011:247923. Article | PubMed Abstract | PubMed Full Text

3. Tubiolo VC, Vazzo LA and Beall GN. Food allergy in human immunodeficiency virus (HIV) infection. Ann Allergy Asthma Immunol. 1997; 78:209-12. | Article | PubMed

4. Krones $E$ and Hogenauer $C$. Diarrhea in the immunocompromised patient. Gastroenterol Clin North Am. 2012; 41:677-701. | Article | PubMed

5. Baden LR and Maguire JH. Gastrointestinal infections in the immunocompromised host. Infect Dis Clin North Am. 2001; 15:639-70, xi. | Article | PubMed

6. Nwaru BI, Hickstein L, Panesar SS, Roberts G, Muraro A and Sheikh A. Prevalence of common food allergies in Europe: a systematic review and meta-analysis. Allergy. 2014; 69:992-1007. | Article | PubMed

7. Stokes SC and Tankersley MS. HIV: practical implications for the practicing allergist-immunologist. Ann Allergy Asthma Immunol. 2011; 107:1-9. | Article | PubMed

Citation:

Salava A, Lauerma A and Kauppi P. Suspected food allergy responding to fluconazole? J Allergy Asthma. 2015; 2:1. http://dx.doi.org/10.7243/2054-9873-2-1 